\title{
INVESTIGATING ACCIDENTS ON THE MAIN ROAD NETWORK IN THE NORTH-WEST REGION OF ROMANIA
}

\author{
RODICA DORINA CADAR ${ }^{1 *}$, ROZALIA MELANIA BOITOR ${ }^{2}$, \\ MARA DUMITRESCU ${ }^{3}$, PETRU DANIEL MĂRAN ${ }^{4}$ \\ ${ }^{1-4}$ Department of Railroads, Roads and Bridges, Technical University of Cluj- \\ Napoca, Cluj-Napoca, Romania
}

Received 3 January 2020; accepted 9 July 2020

\begin{abstract}
The paper investigates the accidents and fatalities on the main road network in the North-West Region of Romania over a period of 4 years (20152018). The aim of the paper is to highlight some shortcomings and suggest possible improvements of the road network in order to reduce the number of accidents and fatalities. Detailed analyses, including statistical and spatial statistical analyses, were conducted on the accidents involving goods and public transport vehicles considering the scale of their impact. As a result, black corridors and vulnerable municipalities were identified. They were found to be related to the reduced main road density and high levels of freight traffic transit. In conclusion, with one of the lowest motorization rates in the EU and given the important efforts already made by the police, improving road network in Romania becomes the key for reducing accident and fatality rates in the region. In this regard, it is suggested that motorways and ring roads are needed in
\end{abstract}

* Corresponding author. E-mail: rodica.cadar@cfdp.utcluj.ro

Rodica Dorina CADAR (ORCID ID 0000-0003-4393-5220)

Rozalia Melania BOITOR (ORCID ID 0000-0002-7694-6543)

Mara DUMITRESCU (ORCID ID 0000-0003-4108-9235)

Petru Daniel MĂRAN (ORCID ID 0000-0001-6387-4328)

Copyright (C) 2021 The Author(s). Published by RTU Press

This is an Open Access article distributed under the terms of the Creative Commons Attribution License (http://creativecommons.org/licenses/by/4.0/), which permits unrestricted use, distribution, and reproduction in any medium, provided the original author and source are credited. 
order to bypass the vulnerable municipalities. The results of this research may enable planners and administrations to act strategically to improve road safety in the critical areas, to prioritize actions for road network development and to formulate better strategies to ensure road safety.

Keywords: Geographic Information System (GIS), goods vehicles, public transport vehicles, road safety, vulnerable municipalities.

\section{Introduction}

Road safety is an essential component of a modern transportation system. Efficiency of the system, including safety, implies a reliable road network with a certain density of the dedicated infrastructure for high-speed and goods vehicles. According to the European Commission (2019), Romania ranks first in the European Union in terms of road fatalities per million inhabitants in 2018, although the evolution over the period of time between 2010 and 2018 presents the same trend as the EU average. Improvements have been made in many areas by the authorities, especially by the Romanian Police. Traffic Department of the General Inspectorate of Romanian Police (TDGIRP) is also part of the CARE project (European Commission, 2018a). However, reducing fatalities on roads is a far more complex problem and road network development is the key issue in this matter.

The National Strategy for Road Safety for the period 2015-2020 (n. d.) specifies that there is no possibility to drastically reduce the number of victims of traffic accidents given the increasing motorization rate and mobility, while road network development is not being carried out at the same rate. The strategy mentions the reduced state of development of road network but none of the objectives addresses the need to increase road network density. At the same time, the need to increase the safety of goods and passenger transport, improving the norms regarding traffic analysis, the regulation of mobility plans, including road safety in the urban planning and spatial planning process are some of the important objectives that are mentioned in the document. An important problem which is highlighted in the strategy refers to urbanization along transit roads - European, national, and county roads, namely, the existing linear localities along them, but there is no recommendation to build ring roads or bypasses.

Previous road safety research in Romania has generally documented the connection between national roads and accident rates (Cadar, Boitor \& Dumitrescu, 2017), vehicle-to-vehicle car crashes (Coșciug, Ciobanu \& Benedek, 2017), spatial characteristics of road traffic accidents and injuries (Ciobanu \& Benedek, 2015), as well as the correlation at the national level between the number of accidents and urbanization level 

were used to clasify dangerous street segments (Benedek, Ciobanu, \& Man, 2016). Vulnerable areas within the city of Cluj-Napoca were identified based on the correlation between low-light conditions and the number of traffic accidents (Ivan, Haidu, Benedek \& Ciobanu, 2015).

Goods vehicles (HGV and LGV) and public transport (PT) vehicles transporting larger number of people run on these types of roads and they represent the main focus in the research, because accidents involving these types of vehicles tend to have a more severe impact and higher costs (Lindberg, 2006). For instance, in Sweden, per kilometre driven, HGV and busses killed five times as many car occupants as passenger cars did (Björnstig, Björnstig \& Eriksson, 2008). Furthermore, road type is important in the analysis of commercial vehicle crashes as these tend to occur on the main roads (59\%) (Kofalvi \& Vincze-Pap, 2001).

In view of these preliminary observations, the paper aims to investigate the accidents and fatalities on the main road network in the North-West Region of Romania in order to highlight some shortcomings and suggest possible improvements to the road network in order to reduce the number of accidents and fatalities. The research focuses on LGV and HGV vehicles along with PT vehicles, highlighting that the low level of road network development is the key factor in accidents occurrence. Addressing the imperative need to improve the road network, the paper argues that the focus should be made on building appropriate infrastructure for high-speed and goods transport, such as motorways, expressways, ring roads, bypasses, and collector streets.

The main road network considered in the study consists of motorways, national and county roads. The black corridors spotted on these roads are seen as input data in analysing road safety issues in the region; they could be considered in the early stages of developing a planning strategy for improving road safety. The scope of the analysis conducted in this paper, namely, analysis at the regional level, provides new insight into road safety issues (Wachnicka, Kustra, Jamoroz \& Budzynski, 2016). As a result, vulnerable municipalities or areas in the region are detected based on the spatial distribution, densities and hotspots of accidents and fatalities. Depending on the statistical relevance of the hotspots, three levels of vulnarability are used to classify the municipalities in the N-W Region of Romania. Therefore, efficent planning strategies can be implemented to improve road safety as long as interventions are prioritised based on the level of vulnerability. Prior actions should be taken by authorities in the deadliest municipalities or wider areas. This methodology was applied 
in the first case study of N-W Region of Romania. It can be considered a simple but innovative and adequate solution for road safety analysis and identification of the critical areas. GIS (Geographic Information System) visualization tools can provide quick and sound information; it appeared useful for assessment of road safety issues. The results may enable administrations to prioritize the actions for road network development and planners and policy makers - to develop better road safety strategies.

The paper comprises the following sections: Introduction, Data and methods, Case study, Results and findings, and finally, Discussion and conclusions.

\section{Data and methods}

The data used in this research are taken from five main sources: Romania National Institute of Statistics, Eurostat, Traffic Department of the General Inspectorate of Romanian Police, OpenStreetMap, Romanian INSPIRE Geoportal.

Datasets from the Romania National Institute for Statistics (2018, 2019) and Eurostat $(2017,2019)$ were employed for the general overview of the transport system and socio-demographics in the N-W Region. The counties in the N-W Region were analysed based on the NIS data. They present specific details referring to population, areas, municipalities, motorization rate, road motor vehicle rate and aspects of the road network, which are extensively presented in the case study. The road network aspects, namely, the length and density, are presented in line with the aim of the research separately for motorways and express roads, national roads, regional roads and bypasses.

New data sets regarding road accidents in the North-West Region of Romania are available. These present specific details referring to locations, participants and vehicles involved in the accidents. Data collection is conducted by the Traffic Department of the General Inspectorate of Romanian Police, who provided the data for the period between 2015 and 2018 for this research in three different datasets regarding incident location, participants and vehicles. A total number of 14244 accidents was recorded, out of which 2020 involved LGV, HGV or PT vehicles. The analysis focuses on the accidents involving goods and public transport vehicles.

Data analyses were performed using Excel. Statistical analyses were conducted using filters, selections and pivot tables in Excel on all three datasets regarding incident location, participants and vehicles. Firstly, vehicles were classified according to the purpose of this research into 
heavy goods vehicles, light goods vehicles and public transport vehicles (busses, mini-busses, coaches, trolleybuses and trams) and others. Goods vehicles and passenger transport vehicles are all considered in the selection due to their load and respective scale of accidents. Vehicles were classified into these categories using such details as brand, model and intended use of the vehicle. If it was not clear whether the vehicle is specifically HGV, LGV or PT, it was not considered. Trailers were not considered either. The most important step in the research was to classify the vehicles according to the Romanian traffic norms, an aspect which was not considered in the data collection process at the time of accident registration. Therefore, the initial database of the accidents was not edited but some new fields were added for the purpose of this research. The most important statistical indicators of this research are accident rate (AR) and fatality rate (FR). AR was calculated as a percentage of the number of accidents that occurred in each county in the total number of accidents (Ciobanu \& Benedek, 2015). AR was also obtained for specific conditions such as HGV, LGV or PT vehicles, location in or outside locality and by type of road. FR was calculated as a percentage of the number of deaths that occurred in each county in the total number of accidents (Pirotti, Guarnieri \& Vettori, 2011). These indicators can be further used for comparison with the previuos studies, which documented the data on the same areas.

GIS analyses were performed using ArcGIS platform. The database provided by TDGIRP was georeferenced. A total number of 13995 georeferenced points were obtained. The accidents located outside the N-W Region were excluded. Furthermore, 2019 accidents involving HGV, LGV or PT vehicles were found in the N-W Region but only 1983 of these points had valid information to support the application of Join tool for connecting the accidents dataset with the vehicles dataset. Three types of analyses with specific tools were used: spatial distribution of the road network, accidents and victims, spatial density of accidents and fatalities, including kernel density of accidents and fatalities, and spatial statistics - average nearest neighbour, Global Moran I and hotspot analysis (Getis-Ord Gi*). Each type of analysis represents one step of the methodology developed in this paper. The proposed methodology has been applied in the first case study of N-W Region of Romania for both accidents and fatalities datasets. The accidents dataset is considered initially to provide some insights into the location of the incidents. Firstly, the spatial distribution of the accidents is used. The simple method helps visualize the accidents by location in order to establish black corridors and to summarize accidents in the municipalities and counties. Secondly, spatial densities are obtained. Heat maps are created, since they are a simple but effective visual tool. Moreover, kernel density interpolation is used. Euclidian kernel density was established based on the results of the Average Nearest Neighbour analysis, which is a
Investigating

Accidents

on the Main Road

Network

in the North-West

Region of Romania 
spatial statistics tool used in this research. An observed mean distance was $1154 \mathrm{~m}$, and experience from the previous research called for using two search radiuses of $1000 \mathrm{~m}$ and $6000 \mathrm{~m}$ (Thakali, Kwon \& Fu, 2015). Obvious differences were established for the two values of the search radius in terms of density, but they confirmed the initial results obtained in the heat maps. Furthermore, they helped formulate the alternative hypothesis that accidents do form spatial clusters in the region for the spatial statistical analysis. Thirdly, the pattern was validated with Global Moran I and Hot Spot analysis (Getis-Ord Gi*). The results of the Global Moran analysis indicated a strong spatial autocorrelation of the accidents. This allowed conducting a more complex pattern analysis within the hotspot analysis. Accident hotspots were identified. They provide a statistically relevant result concerning the critical areas in the region where accident clusters occur. The same three-step methodology was applied to the study of fatalities. Spatial distribution and densities, as well as spatial statistics, were used to identify the vulnerable municipalities or wider areas in the region where more fatal accidents occur.

OpenStreetMap (n. d.) and Romanian INSPIRE Geoportal (n. d.) provided the layers for the GIS representation, the road network and administrative limits in the N-W Region, respectively.

\section{Case study}

Romania is a large country with four first-level NUTS regions (Macroregions, Figure 1a) including eight second-level NUTS regions (Regions, Figure 1b). The study focuses on the North-West Region of Romania (N-W Region), which includes 6 counties: Bihor (BH), BistrițaNăsăud (BN), Cluj (CJ), Maramureș (MM), Satu Mare (SM) and Sălaj (SJ) (Figure 1c).

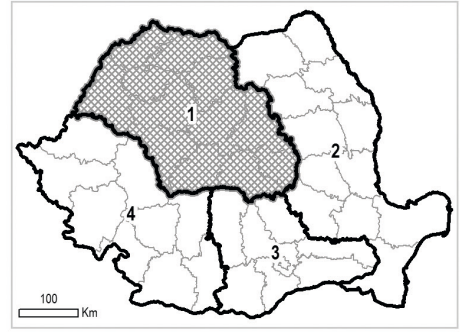

a)

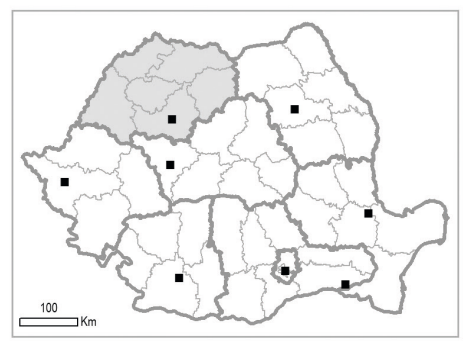

b)

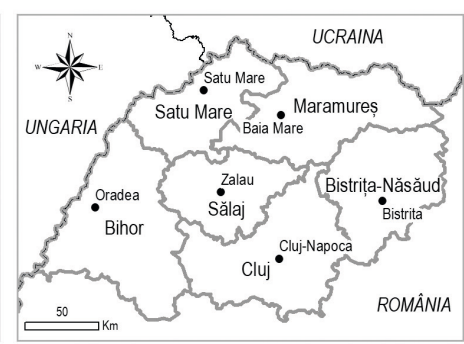

c)

Figure 1. The North-West Region of Romania: a) Macroregion 1 ; b) regions; c) counties of the region 


\subsection{Aspects of the road transportation system}

All three components of the road transportation system in the region are documented - people or users, vehicles and road network - for all six counties: BH, BN, CJ, MM, SM and SJ. The N-W Region has a total population of 2556639 inhabitants and a total area of $34160 \mathrm{~km}^{2}$ as described in Table 1 (Romania National Institute for Statistics, 2019). There are 1911 municipalities in the region, out of which 15 are cities, 28 towns, and 403 communes. CJ has the largest population among the counties of this region, it also has the highest density of population of $106 \mathrm{inh} / \mathrm{km}^{2}$. BH comes second after $\mathrm{CJ}$ in terms of number of residents. The population density in BH is similar to that in SM, MM and the average value in the region. $\mathrm{BH}$ and $\mathrm{CJ}$ have a larger number of municipalities compared to the other counties. The motorization rate in $\mathrm{CJ}$ is 357 cars per 1000 inhabitants, which is not very high compared to $\mathrm{BH}$, which comes second with a motorization rate of 341 cars per 1000 inhabitants. The motorization rate in the $\mathrm{N}-\mathrm{W}$ Region with 333 cars per 1000 inhabitants is almost equal to the national rate (Romania National Institute for Statistics, 2019). In this respect, Romania comes last in the EU (Eurostat, 2017). When considering road motor vehicles per 1000 inhabitants, the N-W Region demonstrates a slightly higher rate than the national one. While
Rodica Dorina Cadar, Rozalia Melania

Boitor,

Mara Dumitrescu,

Petru Daniel Măran

Investigating

Accidents

on the Main Road

Network

in the North-West

Region of Romania

Table 1. Characteristics of the counties in the N-W Region of Romania (source: author*, 2018)

\begin{tabular}{|c|c|c|c|c|c|c|c|c|}
\hline 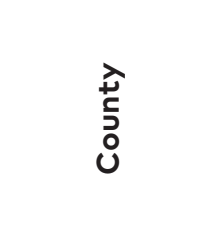 & 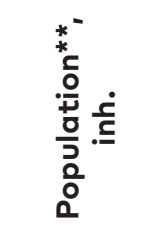 & 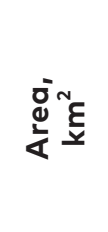 & 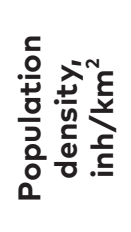 & 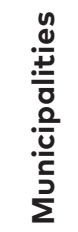 & 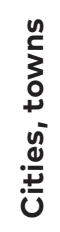 & 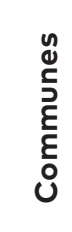 & 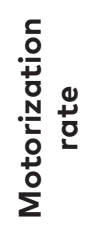 & 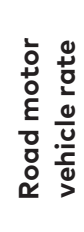 \\
\hline $\mathrm{BH}$ & 562750 & 7544 & 75 & 458 & 10 & 91 & 341 & 447 \\
\hline $\mathrm{BN}$ & 279500 & 5355 & 52 & 249 & 4 & 58 & 302 & 396 \\
\hline CJ & 705914 & 6674 & 106 & 434 & 6 & 75 & 357 & 456 \\
\hline $\mathrm{MM}$ & 462012 & 6304 & 73 & 247 & 13 & 63 & 307 & 396 \\
\hline SM & 333627 & 4418 & 76 & 234 & 6 & 59 & 330 & 427 \\
\hline SJ & 212836 & 3864 & 55 & 289 & 4 & 57 & 329 & 427 \\
\hline $\begin{array}{c}\text { Total } \\
\text { (N-W Region) }\end{array}$ & 2556639 & 34160 & 75 & 1911 & 43 & 403 & 333 & 430 \\
\hline
\end{tabular}

Note: ${ }^{*}$ based on the NIS data; ${ }^{* *}$ usually resident population as of July 1st, 2018 (provisional data). 
Table 2. Road network in the N-W Region of Romania (source: author*, 2018)

\begin{tabular}{|c|c|c|c|c|c|c|c|c|}
\hline 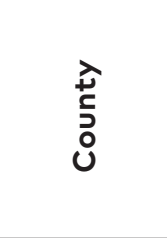 & 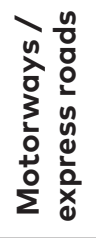 & 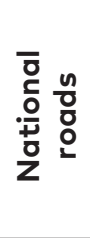 & 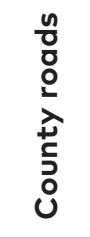 & $\begin{array}{l}\frac{n}{0} \\
0 \\
0 \\
\frac{0}{0} \\
0\end{array}$ & 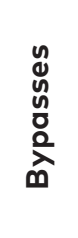 & 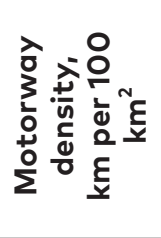 & 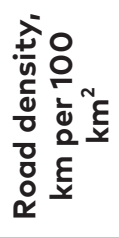 & 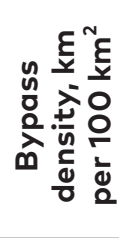 \\
\hline $\mathrm{BH}$ & 0 & 528 & 990 & 1485 & 36.4 & 0 & 39.8 & 0.48 \\
\hline $\mathrm{BN}$ & 0 & 315 & 698 & 583 & 6.9 & 0 & 29.8 & 0.13 \\
\hline CJ & 68 & 566 & 1279 & 983 & 34.4 & 1.02 & 42.4 & 0.52 \\
\hline $\mathrm{MM}$ & 0 & 371 & 785 & 653 & 7.6 & 0 & 28.7 & 0.12 \\
\hline SM & 0 & 303 & 838 & 570 & 10.5 & 0 & 38.7 & 0.24 \\
\hline SJ & 0 & 286 & 632 & 873 & 13.2 & 0 & 46.3 & 0.34 \\
\hline $\begin{array}{c}\text { Total (N-W } \\
\text { Region) }\end{array}$ & 68 & 2369 & 5222 & 5147 & 109 & 0.2 & 37.3 & 0.32 \\
\hline
\end{tabular}

Note: * values reported by the NIS.

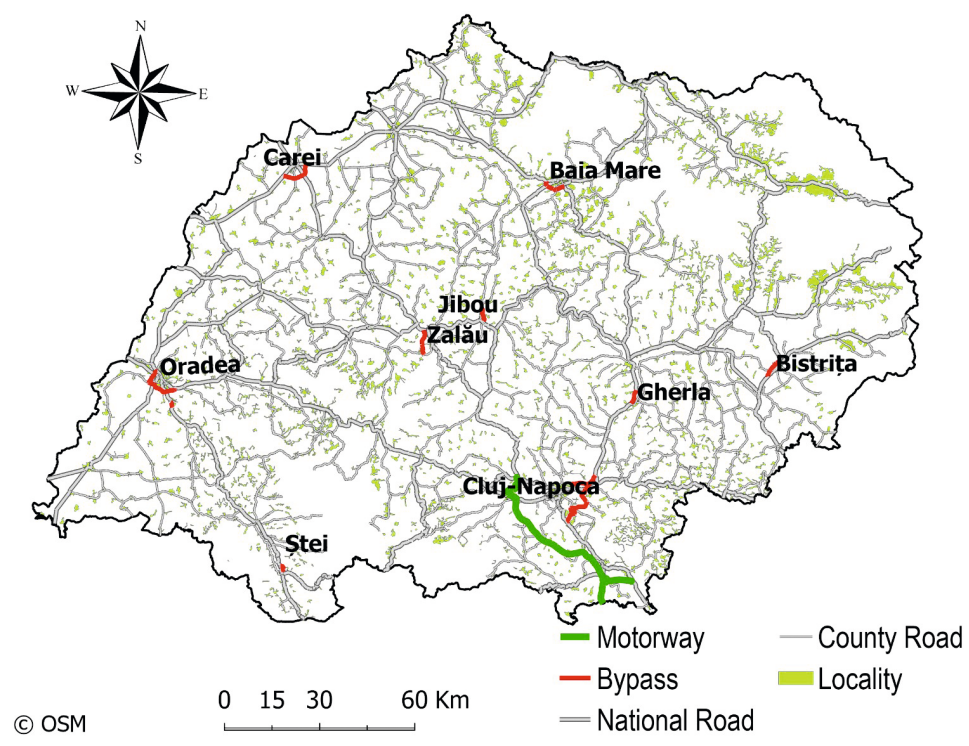

Figure 2. The motorways and bypasses in the N-W Region of Romania, 2019

motorization rate in the N-W Region has increased over the study period, from 261 to 333 cars per 1000 inhabitants, road network density did not vary significantly, increasing by $59 \mathrm{~km}$ in the total length (Romania National Institute for Statistics, 2019). 
Table 2 presents the data on the road network summarized by the Petru Daniel Măran

Investigating

Accidents Romania National Institute for Statistics (2018). The road network includes all roads in the N-W Region: motorways and express roads, national roads, regional or county roads, and other urban and rural or local roads. According to the Romanian norms, streets are considered differently from roads. The length of the national roads in CJ is $566 \mathrm{~km}$, followed closely by BH with $528 \mathrm{~km}$. CJ is the only county that has an operational motorway with a length of $68 \mathrm{~km}$. There are no express roads in the region. According to Government Decision No. 782 (The Government of Romania, 2014), not a single city or town in the N-W Region has a ring road. However, Cluj-Napoca (CJ), Gherla (CJ) and Oradea (BH) have some bypasses that run outside the localities and Bistrița (BN) and Ștei (BH) have some links, which are named bypasses but they run throughout the localities passing by the central area. In total, 9 out of 43 cities and towns in the N-W Region have bypasses, with a total length of $109 \mathrm{~km}$. The motorways and bypasses in the N-W Region in 2019 are illustrated in Figure 2. According to Knoema (n. d.), road density is the ratio of the length of the country's total road network to the country's land area. Road density in the N-W Region is very close to the national value of $36 \mathrm{~km}$ per $100 \mathrm{~km}^{2}$. Although the road network density and motorway density in the N-W region is slightly above the national value, they are still very low.

\subsection{Road accident-related aspects}

During the 4-year period, between 2015 and 2018, TDGIRP recorded 14244 accidents in the N-W Region. It resulted in 5.6 accidents per 1000 people. In total, 21702 vehicles and 19172 people were involved in all accidents, resulting in 964 fatalities. Table 3 presents an overview of the initial statistical analysis. It provides insights into the type and number of vehicles involved in the accidents, incidence of events by locality and type of road, and the number of fatalities. Table 4 presents accident and fatality rates for each county of the region. It shows that $34 \%$ of the accidents were registered in CJ. This percentage is four times higher than that of the county with the lowest number of accidents, namely, SM. Accidents involving $\mathrm{HGV}, \mathrm{LGV}$ and $\mathrm{PT}$ vehicles were considered for a more detailed analysis. $13 \%$ of the accidents in the region involved at least one HGV, LGV or PT vehicle, $45 \%$ of the accidents occurred on the main road network, $81 \%$ of the accidents occurred inside a locality. CJ is the county with the highest AR. Some general observations on the material losses in accidents are related to the number of vehicles involved. A total of $3705 \mathrm{HGV}, \mathrm{LGV}$, and PT vehicles were involved in 
Table 3. Accidents database overview (source: author*, 2019)

\begin{tabular}{|c|c|c|c|c|c|c|c|c|c|c|c|c|c|c|}
\hline \multirow[b]{2}{*}{ 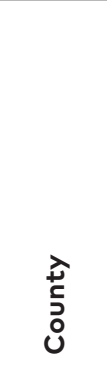 } & \multirow[b]{2}{*}{ 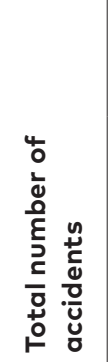 } & \multirow[b]{2}{*}{ 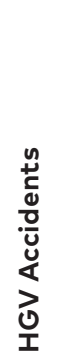 } & \multirow[b]{2}{*}{ 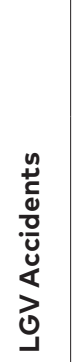 } & \multirow[b]{2}{*}{ 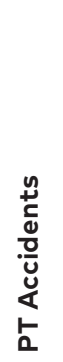 } & \multicolumn{2}{|c|}{$\begin{array}{l}\text { Accident } \\
\text { location in } \\
\text { the locality }\end{array}$} & \multicolumn{6}{|c|}{$\begin{array}{l}\text { Accident location } \\
\text { on the road network }\end{array}$} & \multirow[b]{2}{*}{ 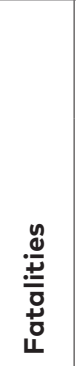 } & \multirow[b]{2}{*}{ 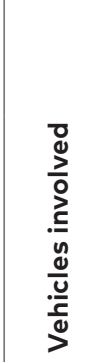 } \\
\hline & & & & & $\stackrel{\frac{0}{0}}{\frac{0}{n}}$ & $\begin{array}{l}\frac{0}{0} \\
\frac{0}{n} \\
03\end{array}$ & 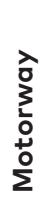 & 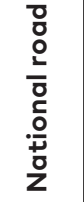 & 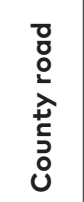 & $\begin{array}{l}\frac{8}{0} \\
\overline{0} \\
\check{J} \\
\varepsilon \\
\varepsilon \\
0 \\
0\end{array}$ & 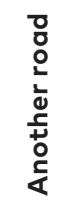 & $\begin{array}{l}\stackrel{4}{0} \\
\dot{\Xi} \\
\dot{\omega}\end{array}$ & & \\
\hline $\mathrm{BH}$ & 2118 & 171 & 131 & 48 & 1625 & 493 & 0 & 598 & 378 & 174 & 33 & 935 & 168 & 3261 \\
\hline $\mathrm{BN}$ & 2238 & 125 & 157 & 53 & 1853 & 385 & 0 & 967 & 420 & 172 & 32 & 647 & 156 & 3286 \\
\hline CJ & 4908 & 215 & 269 & 240 & 4176 & 732 & 23 & 1223 & 405 & 116 & 238 & 2903 & 236 & 7843 \\
\hline MM & 2405 & 111 & 116 & 54 & 2024 & 381 & 0 & 603 & 465 & 76 & 63 & 1198 & 161 & 3600 \\
\hline SM & 1232 & 67 & 93 & 21 & 1002 & 230 & 0 & 316 & 183 & 17 & 3 & 713 & 139 & 1805 \\
\hline SJ & 1343 & 95 & 22 & 32 & 934 & 409 & 0 & 488 & 283 & 143 & 10 & 419 & 104 & 1907 \\
\hline $\begin{array}{l}\text { Total } \\
\text { N-W } \\
\text { Region }\end{array}$ & 14244 & 784 & 788 & 448 & 11614 & 2630 & 23 & 4195 & 2134 & 698 & 379 & 6815 & 964 & 21702 \\
\hline
\end{tabular}

Note: * based on the data.

Table 4. Accident rate and fatality rate by county (source: author*, 2019)

\begin{tabular}{|c|c|c|c|c|c|c|c|c|c|c|c|c|c|c|c|}
\hline \multirow[b]{2}{*}{ 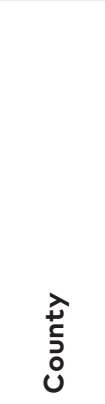 } & \multirow[b]{2}{*}{ 娄 } & \multirow[b]{2}{*}{$\begin{array}{l}\frac{\alpha}{\alpha} \\
\vdots \\
0 \\
1\end{array}$} & \multirow[b]{2}{*}{ 号 } & \multirow[b]{2}{*}{$\begin{array}{l}\stackrel{\alpha}{\alpha} \\
\stackrel{\leftarrow}{\alpha}\end{array}$} & \multirow[b]{2}{*}{ 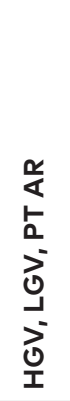 } & \multicolumn{2}{|c|}{$\begin{array}{c}\text { AR by } \\
\text { location in } \\
\text { the locality }\end{array}$} & \multicolumn{7}{|c|}{ AR by road type } & \multirow[b]{2}{*}{ 愛 } \\
\hline & & & & & & 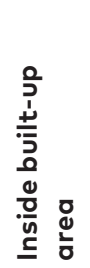 & 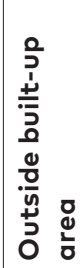 & $\begin{array}{l}\frac{\alpha}{4} \\
\lambda \\
0 \\
3 \\
1 \\
0 \\
0 \\
0 \\
\Sigma\end{array}$ & 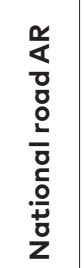 & 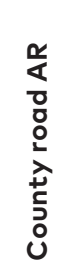 & 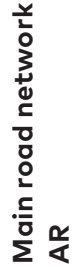 & 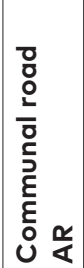 & 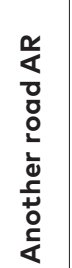 & 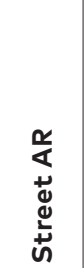 & \\
\hline $\mathrm{BH}$ & $15 \%$ & $1 \%$ & $1 \%$ & $0 \%$ & $2 \%$ & $11 \%$ & $3 \%$ & $0 \%$ & $4 \%$ & $3 \%$ & $7 \%$ & $1 \%$ & $0 \%$ & $7 \%$ & $1 \%$ \\
\hline $\mathrm{BN}$ & $16 \%$ & $1 \%$ & $1 \%$ & $0 \%$ & $2 \%$ & $13 \%$ & $3 \%$ & $0 \%$ & $7 \%$ & $3 \%$ & $10 \%$ & $1 \%$ & $0 \%$ & $5 \%$ & $1 \%$ \\
\hline CJ & $34 \%$ & $2 \%$ & $2 \%$ & $2 \%$ & $5 \%$ & $29 \%$ & $5 \%$ & $0 \%$ & $9 \%$ & $3 \%$ & $12 \%$ & $1 \%$ & $2 \%$ & $20 \%$ & $2 \%$ \\
\hline MM & $17 \%$ & $1 \%$ & $1 \%$ & $0 \%$ & $2 \%$ & $14 \%$ & $3 \%$ & $0 \%$ & $4 \%$ & $3 \%$ & $7 \%$ & $1 \%$ & $0 \%$ & $8 \%$ & $1 \%$ \\
\hline SM & $9 \%$ & $0 \%$ & $1 \%$ & $0 \%$ & $1 \%$ & $7 \%$ & $2 \%$ & $0 \%$ & $2 \%$ & $1 \%$ & $4 \%$ & $0 \%$ & $0 \%$ & $5 \%$ & $1 \%$ \\
\hline SJ & $9 \%$ & $1 \%$ & $0 \%$ & $0 \%$ & $1 \%$ & $7 \%$ & $3 \%$ & $0 \%$ & $3 \%$ & $2 \%$ & $5 \%$ & $1 \%$ & $0 \%$ & $3 \%$ & $1 \%$ \\
\hline $\begin{array}{l}\text { Total } \\
\mathrm{N}-\mathrm{W} \\
\text { Region }\end{array}$ & $100 \%$ & $6 \%$ & $6 \%$ & $2 \%$ & $13 \%$ & $81 \%$ & $19 \%$ & $0 \%$ & $29 \%$ & $15 \%$ & $45 \%$ & $5 \%$ & $2 \%$ & $48 \%$ & $7 \%$ \\
\hline
\end{tabular}

Note: * based on the TDGIRP data. 


\section{Results and findings}

A total number of 14244 accidents were recorded in the North-West Region over the study period, between 2015 and 2018, out of which 2020 involved LGV, HGV or PT vehicles. The outcome of the accidents and fatality rates of the accidents involving HGV, LGV and PT vehicles by county presented in Table 5 show that $36 \%$ of the accidents involving HGV, LGV and PT vehicles were registered in CJ, 17\% in $\mathrm{BN}, 17 \%$ in $\mathrm{BH}$, $14 \%$ in $\mathrm{MM}, 6 \%$ in SM and $10 \%$ in SJ. The fatality rates follow a similar trend in the counties, namely, $3 \%$ in $\mathrm{CJ}$ and $\mathrm{BH}, 2 \%$ in $\mathrm{BN}$, respectively, $1 \%$ in MM, SM and SJ. The statistical analysis of the accidents involving LGV, HGV and PT shows that these accidents mainly occurred

Table 5. Accident and fatality rates of accidents involving HGV, LGV and PT vehicles by county (source: author*, 2019)

\begin{tabular}{|c|c|c|c|c|c|c|c|c|c|c|c|c|c|c|c|c|c|c|}
\hline \multirow{2}{*}{ 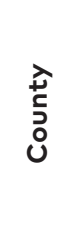 } & \multicolumn{5}{|c|}{$\begin{array}{c}\text { Total accidents including } \\
\text { HGV, LGV, and PT } \\
\text { vehicles }\end{array}$} & \multicolumn{4}{|c|}{$\begin{array}{c}\text { Inside the built-up } \\
\text { area }\end{array}$} & \multicolumn{4}{|c|}{ Main road network } & \multicolumn{4}{|c|}{ Street network } & \multirow{2}{*}{ 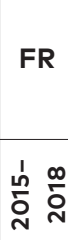 } \\
\hline & ำ & $\stackrel{\text { ำ }}{\circ}$ & 윰 & స̃ & $\stackrel{\infty}{D_{N}}$ & 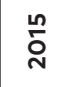 & 윰 & $\stackrel{N}{\circ}$ & $\stackrel{\infty}{\infty}$ & ำ & 유 & ơ & $\stackrel{\infty}{\circ}$ & $\stackrel{n}{\circ}$ & 유 & 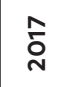 & $\stackrel{\infty}{\infty}$ & \\
\hline$\frac{T}{m}$ & $17 \%$ & $18 \%$ & $18 \%$ & $17 \%$ & $17 \%$ & $11 \%$ & $12 \%$ & $12 \%$ & $12 \%$ & $11 \%$ & $11 \%$ & $9 \%$ & $12 \%$ & $6 \%$ & $6 \%$ & $6 \%$ & $3 \%$ & $3 \%$ \\
\hline$z_{m}$ & $17 \%$ & $16 \%$ & $14 \%$ & $18 \%$ & $20 \%$ & $13 \%$ & $11 \%$ & $14 \%$ & $15 \%$ & $11 \%$ & $10 \%$ & $14 \%$ & $14 \%$ & $4 \%$ & $2 \%$ & $3 \%$ & $4 \%$ & $2 \%$ \\
\hline $\mathcal{U}$ & $36 \%$ & $33 \%$ & $40 \%$ & $36 \%$ & $34 \%$ & $27 \%$ & $31 \%$ & $27 \%$ & $27 \%$ & $15 \%$ & $18 \%$ & $15 \%$ & $15 \%$ & $16 \%$ & $19 \%$ & $18 \%$ & $17 \%$ & $3 \%$ \\
\hline$\sum_{\Sigma}$ & $14 \%$ & $17 \%$ & $13 \%$ & $13 \%$ & $13 \%$ & $14 \%$ & $11 \%$ & $9 \%$ & $9 \%$ & $8 \%$ & $7 \%$ & $7 \%$ & $6 \%$ & $8 \%$ & $6 \%$ & $5 \%$ & $6 \%$ & $1 \%$ \\
\hline$\sum_{n}$ & $6 \%$ & $4 \%$ & $5 \%$ & $7 \%$ & $7 \%$ & $2 \%$ & $3 \%$ & $5 \%$ & $6 \%$ & $4 \%$ & $4 \%$ & $4 \%$ & $4 \%$ & $1 \%$ & $1 \%$ & $2 \%$ & $3 \%$ & $1 \%$ \\
\hline$\vec{v}$ & $10 \%$ & $12 \%$ & $10 \%$ & $10 \%$ & $9 \%$ & $7 \%$ & $5 \%$ & $6 \%$ & $5 \%$ & $8 \%$ & $6 \%$ & $8 \%$ & $6 \%$ & $3 \%$ & $2 \%$ & $2 \%$ & $2 \%$ & $1 \%$ \\
\hline 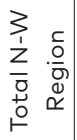 & $\begin{array}{l}\circ \\
\stackrel{\circ}{\circ} \\
\circ\end{array}$ & $\begin{array}{l}\circ \\
\stackrel{\circ}{\circ} \\
\circ\end{array}$ & $\begin{array}{l}\stackrel{\circ}{\circ} \\
\stackrel{\circ}{\circ}\end{array}$ & $\begin{array}{l}\stackrel{\circ}{\circ} \\
\stackrel{\circ}{\circ}\end{array}$ & $\begin{array}{l}\stackrel{\circ}{\circ} \\
\stackrel{\circ}{\circ}\end{array}$ & 吕 & $\stackrel{\circ}{\stackrel{0}{N}}$ & $\stackrel{\circ}{\stackrel{\circ}{N}}$ & $\stackrel{\circ}{\stackrel{\circ}{N}}$ & $\stackrel{\circ}{\stackrel{2}{ก}}$ & $\stackrel{\circ}{\stackrel{2}{ก}}$ & $\stackrel{\circ}{\circ}$ & $\stackrel{\circ}{\stackrel{2}{人}}$ & $\begin{array}{l}\stackrel{\circ}{\circ} \\
\stackrel{m}{m}\end{array}$ & 。̊ & 。̊ & 유ํ & $\stackrel{\circ}{\circ}$ \\
\hline
\end{tabular}

Note: * based on the TDGIRP data. 

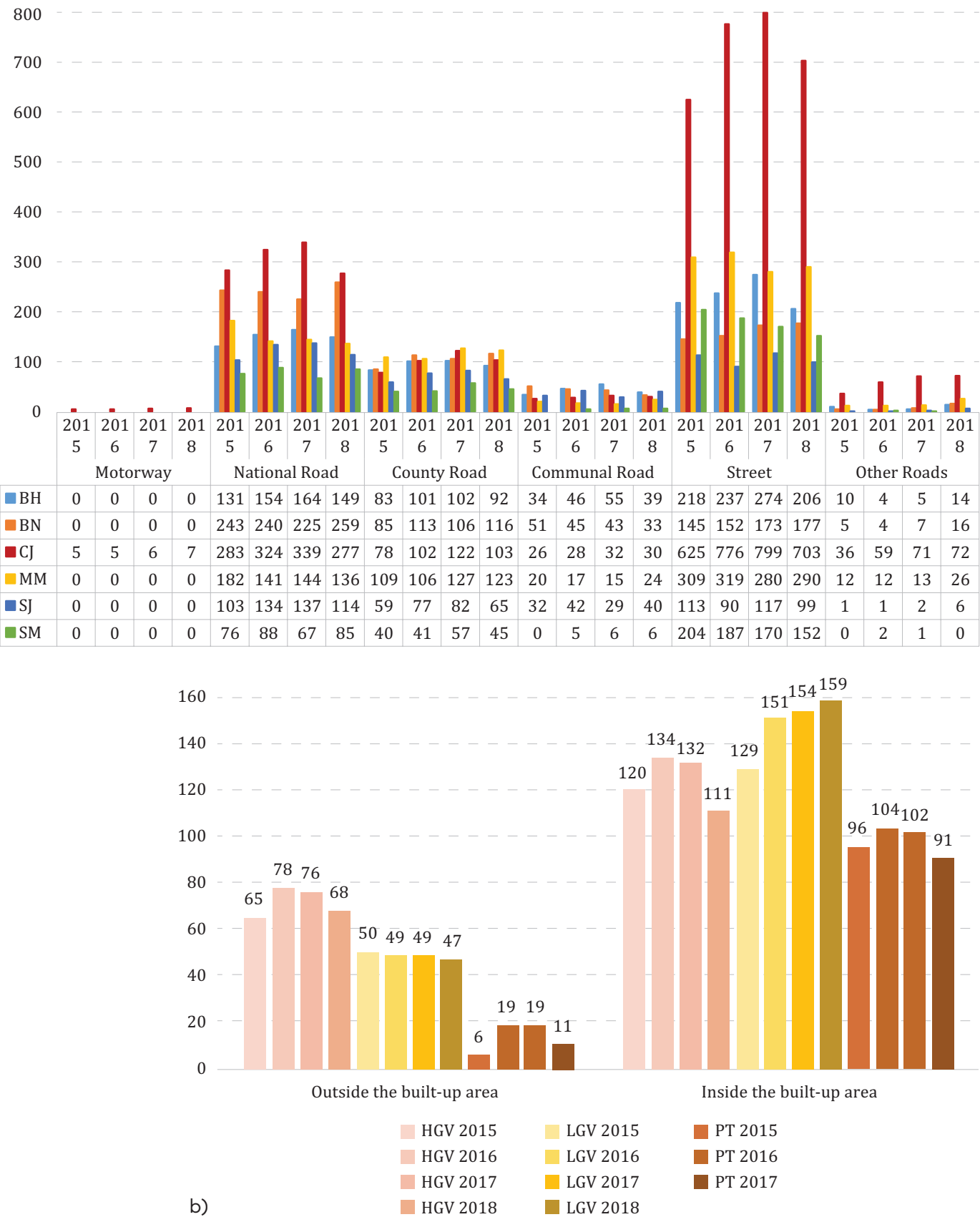

Figure 3. Accidents involving HGV, LGV and PT vehicles in the N-W Region between 2015 and 2018: a) incidence by type of road; b) incidence in or outside a locality 
within built-up areas of localities and along the main road network Mara Dumitrescu, Petru Daniel Măran (Figures 3a, 3b; Table 5). The highest fatality rate was recorded in CJ and $\mathrm{BH}$.

A total number of 13995 points were georeferenced, out of which 2019 points were accidents involving HGV, LGV or PT. Only 1983 of these points had valid information to support the Join tool for connecting the accidents dataset with the vehicles dataset. The methodology, which was developed and applied for the case study, involved conducting three types of GIS analysis, namely spatial distributions, spatial densities and spatial statistics, for both accidents and fatalities datasets. GIS analyses were performed using spatial distribution of the road network, accidents and victims, spatial density of accidents and fatalities, including kernel density of accidents and fatalities and spatial statistics - average nearest neighbour, Global Moran I and hotspot analysis (Getis-Ord Gi*).

Firstly, the spatial distribution of the accidents helps to visualize the accidents by location and to establish the black corridors in the N-W Region.

The map presented in Figure $4 \mathrm{a}$ shows the location of accidents involving $\mathrm{HGV}$, LGV and PT vehicles, validates the numerical data presented previously in the charts and tables, and provides a perspective on the black corridors in the N-W Region.

Secondly, spatial densities are obtained using the heat map and kernel density interpolation tools.

Figure $4 \mathrm{~b}$ presents the results of the kernel analysis, it validates the presence of black corridors in the first map. The analysis was conducted using a round value of $1000 \mathrm{~m}$ for the search radius, which is very close to the observed mean distance of $1154 \mathrm{~m}$ that resulted from the Average Nearest Neighbour analysis. A maximum density of 1.14 accidents per cell was obtained.

Summing up the accidents in municipalities shows the vulnerable municipalities with higher accident incidence. This helps identify the critical areas in the N-W Region. Figures $5 \mathrm{a}$ and $5 \mathrm{~b}$ present the two sides of the same coin, namely, a sum of the accidents involving HGV, LGV and PT vehicles within municipalities against their heat map. Kernel analysis was conducted using a search radius of $6000 \mathrm{~m}$, namely, six times the closest round value of the observed mean distance. The outcome of a maximum density of 4.35 accidents per cell is presented in Figure 5c.

Thirdly, the pattern was validated with spatial statistics indicators, such as Global Moran I and Hot Spot analysis (Getis-Ord Gi*). The Global Moran analysis of the accidents reported a value of 0.0591 for Global Moran's Index, a Z-score of 4.606 and a $p$-value of 0.000004 . The results indicate that there is a strong spatial autocorrelation of 


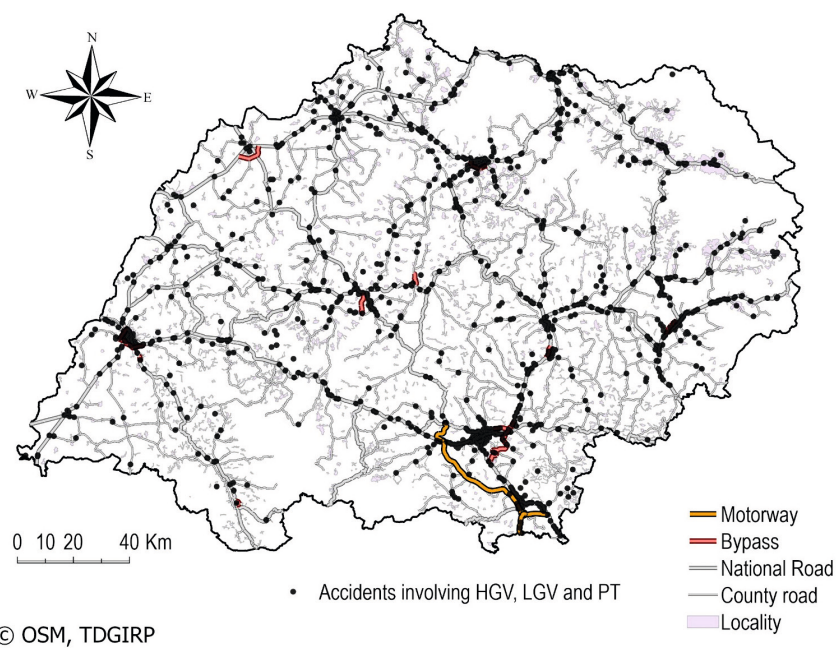

b)

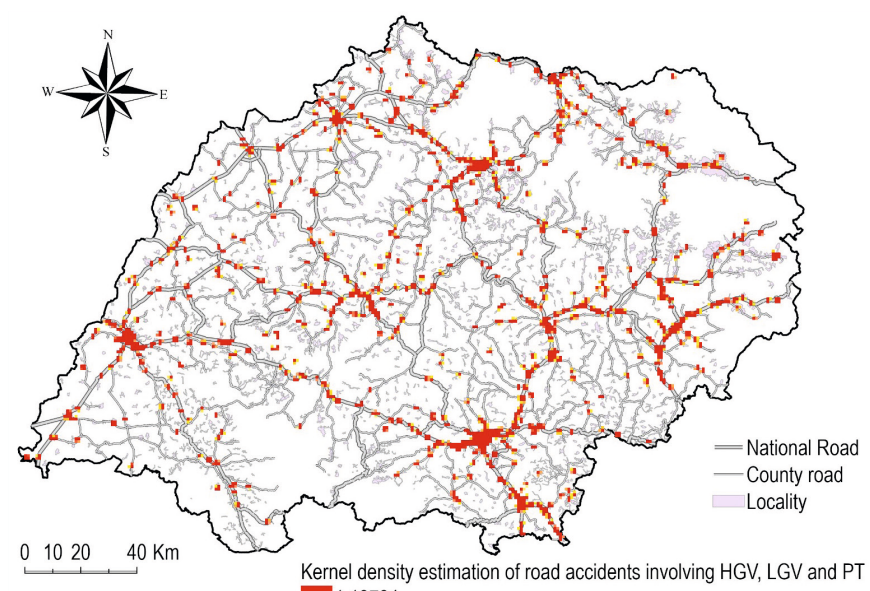

(c) OSM, TDGIRP

Figure 4. Accidents involving HGV, LGV and PT vehicles in the North-West Region of Romania: a) location on the main road network; b) kernel density

the accidents. This facilitated the hotspot analysis. Accident hotspots were identified (Figure 5d). Hotspot analysis was conducted to provide a statistically relevant result concerning the critical areas in the region where accident clusters occur. The accident hotspots are clustered in the metropolitan area of Cluj-Napoca (red cells in Figure $5 \mathrm{~d})$. The regional urban centre of Cluj-Napoca is the most vulnerable city and the hotspots clustered around the city are the most vulnerable municipalities in the region. 


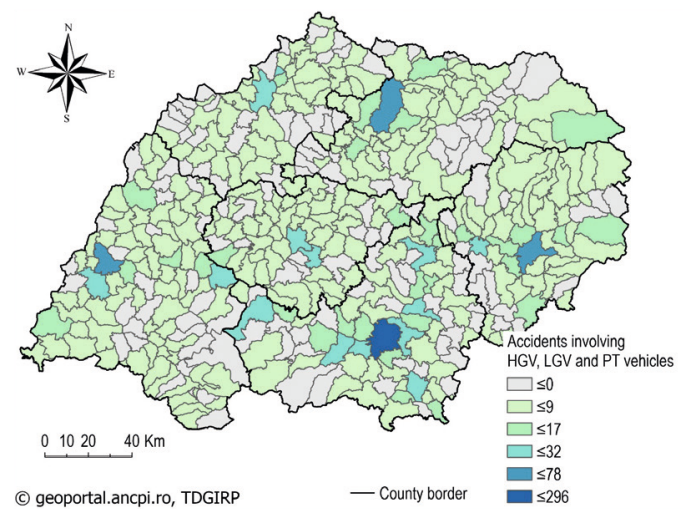

a)

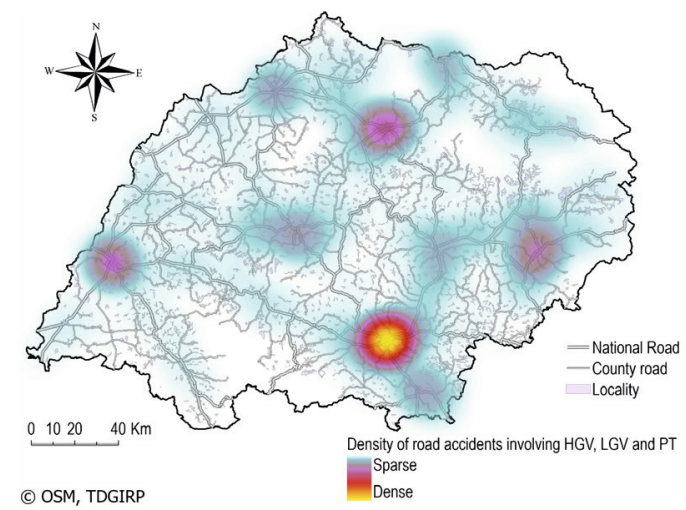

c)

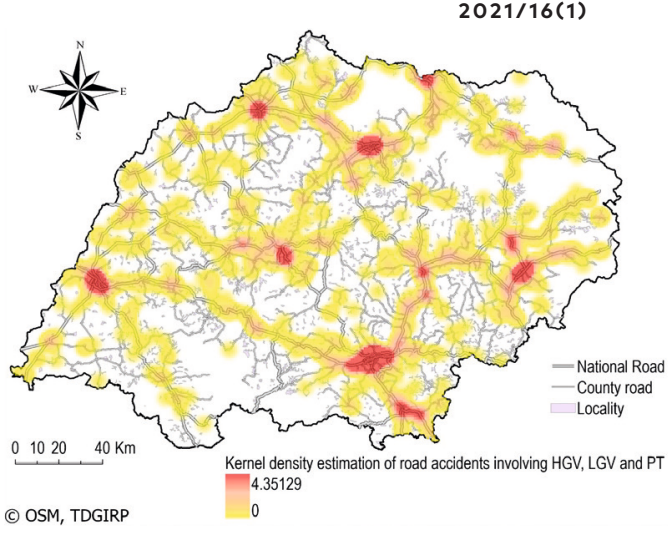

b)

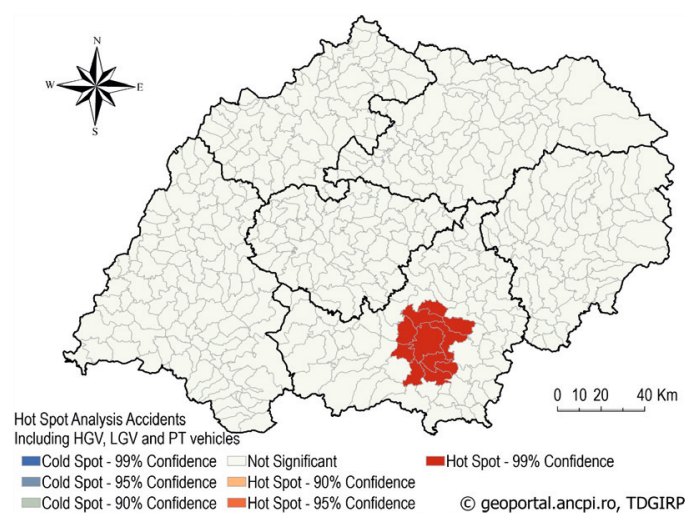

d)

Figure 5. GIS analyses of the accidents involving HGV, LGV and PT vehicles in the North-West Region of Romania over the period between 2015 and 2018:

a) sum in municipalities; b) accidents heat map; c) accidents kernel density;

d) accident hotspots

Every accident has a negative impact, particularly in terms of the lost lives. In total, 238 lives were lost between 2015 and 2018 in the N-W Region in the accidents involving HGV, LGV and PT vehicles, which represented $25 \%$ of the total fatalities in the region. The percentage is higher than the $16-18 \%$ of fatalities resulting from accidents involving HGV busses and coaches registered within the EU in the period between 2007 and 2016 (European Commission, 2018b). Although the number of fatalities (238 people) is lower than that of severely injured (787 people) and slightly injured (1750 people), still those lives are lost. 

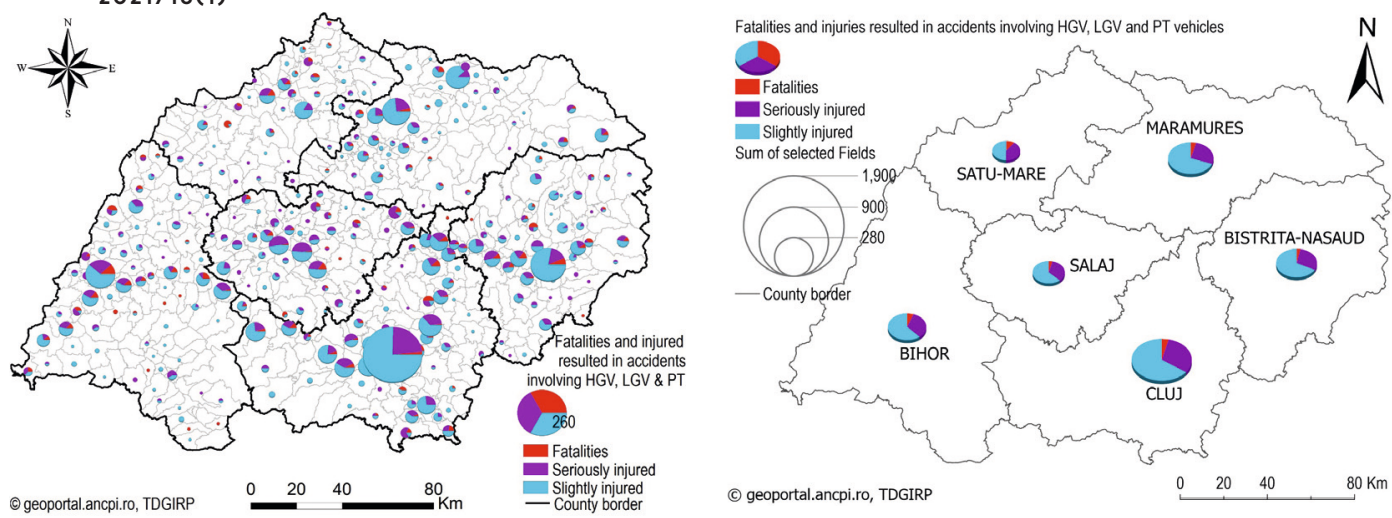

a)

b)
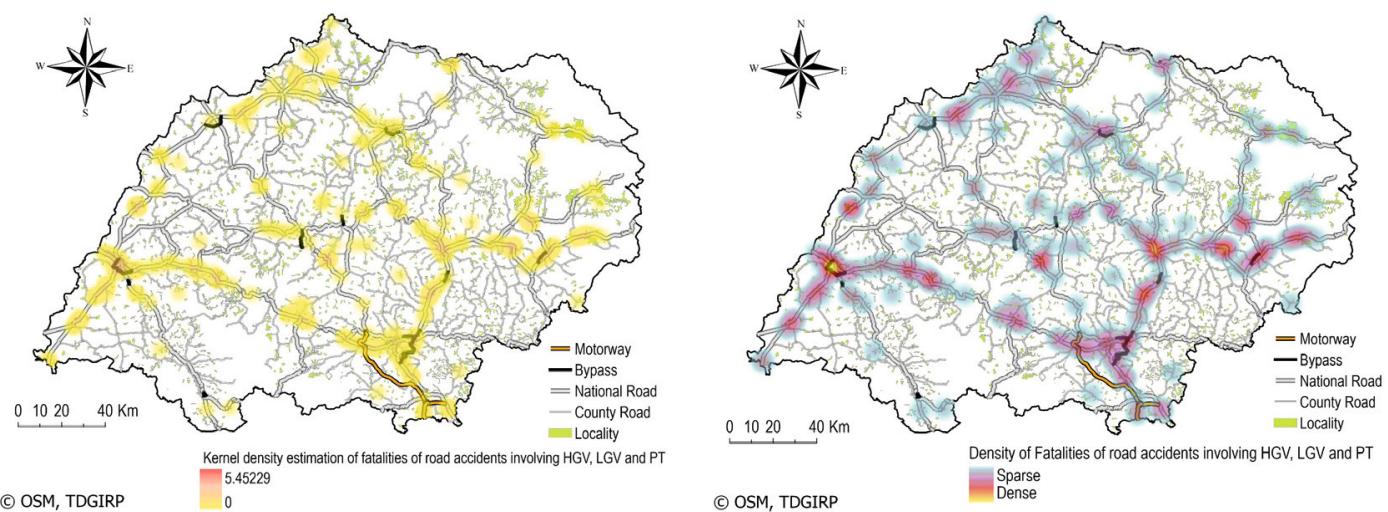

$\begin{array}{cc}\text { Density of } & \text { Sparse } \\ \text { Dense } & \\ \text { De OSM, TDGIRP } & \end{array}$

d)

c)

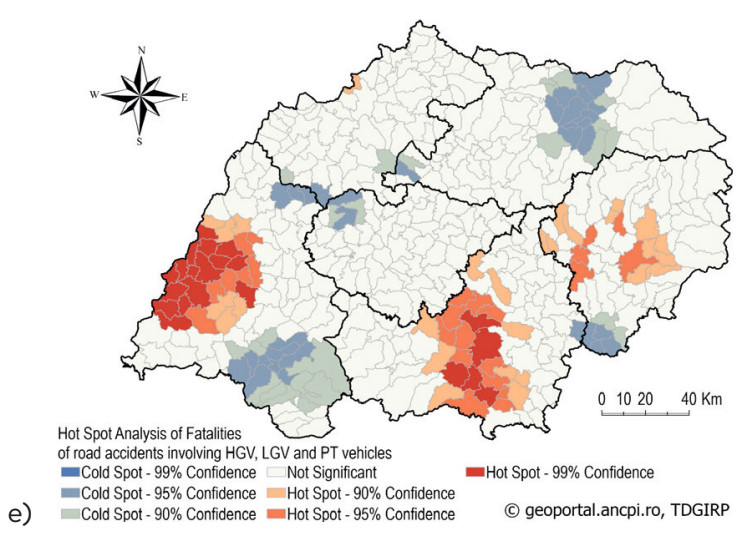

Figure 6. Victims of HGV, LGV and PT accidents in the N-W Region over the period between 2015 and 2018: a) fatalities, seriously injured and slightly injured summarized in the municipalities; b) fatalities, seriously injured and slightly injured summarized in the counties; c) fatalities heat map; d) fatalities kernel density; e) fatalities hotspots and cold spots 
The impact of accidents involving LGV, HGV and TP on traffic Mara Dumitrescu, Petru Daniel Măran

Investigating Accidents conditions remains an important factor, especially since accident localities are concentrated in the urban areas and along the national roads, given the extremely high density of linear municipalities along these roads (Figure 6a). This aspect may be considered in more detail when comparing the results of the summarization per municipality to those of the summarization per county (Figure 6b). Moreover, the descending trend of the lives lost in these accidents, namely, 62 in 2015, 59 in 2016 and 52 in 2017 changed to 65 deaths in 2018. The fatalities heat map in Figure $6 \mathrm{c}$ shows a similar picture to the accidents heat map. The kernel density of the fatalities is presented in Figure 6d. A maximum density of 5.45 accidents per cell was obtained using a search radius of $6000 \mathrm{~m}$. The pattern was validated with spatial statistics indicators, such as Global Moran I and Hot Spot analysis. The Global Moran analysis of the fatalities reported a value of 0.082586 for Global Moran's Index, a $Z$-score of 4.086 and a $p$-value of 0.000044 . The results indicated a strong spatial autocorrelation of the fatalities. This allowed conducting a more complex pattern analysis within the hotspot analysis. Fatalities hotspots were obtained (Figure 6e) to provide a statistically relevant result concerning the critical areas and to identify the vulnerable municipalities or wider areas in the region where more fatalities are registered. Fatalities hotspots show that critical areas are found in important urban municipalities and wider areas clustered around them. It is the case of the metropolitan area of Oradea located near the border, the regional pole of Cluj-Napoca and some linear municipalities situated on the main road network in BN. However, some municipalities demonstrate a totally different situation, an opposite trend highlighted by the cold spots, which present a desirable goal - statistically relevant safe areas.

\section{Discussion and conclusions}

The paper investigates the accidents and fatalities on the main road network in the North-West Region of Romania over the period of 4 years (2015-2018). Since 964 people died on the roads of the N-W Region of Romania between 2015 and 2018, there is an urgent need to act to improve road safety in order to reduce the social costs of accidents.

The transport system in the region is extensively documented in terms of people, vehicles and road network for all six counties: BH, BN, CJ, MM, SM and SJ. The N-W Region has a total population of 2556639 inhabitants and a total area of $34160 \mathrm{~km}^{2}$. Population is the largest and demonstrates the highest density in CJ. BH comes second 
after $\mathrm{CJ}$ in terms of the number of residents. The population density in $\mathrm{BH}$ is similar to that in $\mathrm{SM}, \mathrm{MM}$ and the average value in the region. $\mathrm{BH}$ and $\mathrm{CJ}$ have a larger number of municipalities compared to the other counties. The motorization rate is comparable among the counties. With 333 cars per 1000 inhabitants in the N-W Region, the motorization rate is almost equal to the national rate, it is one of the lowest in the EU. The length of the main road network in the region is reduced, the only operational motorway has a length of $68 \mathrm{~km}$, there are no express roads and not a single city or town has a ring road.

These data were analysed along with the road accidents database provided by TDGIRP consisting of three datasets regarding incident location, participants and vehicles. The complex accidents database, which provides foundation for this research, was provided by TDGIRP, which has already made many improvements to increase road safety.

Accident and fatality rates were calculated and explicitly presented. Detailed analyses, including statistical and spatial statistical analyses, were conducted on the accidents involving goods and public transport vehicles due to the scale of their impact.

As a result, the highest number of accidents as well as that of fatalities was mostly found along the main roads and in the built-up areas of municipalities. Practically, this is related to the reduced road density and high levels of freight traffic transit in the populated areas. One solution to this problem would be to increase road density by building motorways or ring roads that bypass the localities. Furthermore, limiting the expansion of the urban areas along the existing roads by imposing restrictions in the urban planning documents may also be part of the solution. Without these measures and in the absence of an urban development strategy, there is a risk that by expanding linear municipalities, an even greater share of national roads will become mixed-function links, offering both mobility and local accessibility and thus reduced road safety because of traffic conflicts and low average speeds.

In conclusion, given one of the lowest motorization rates in the EU and the important efforts already made by the police, improvement of the road network in Romania becomes the key to reducing accidents and fatalities in the region.

Spatial distribution concepts, such as location of points on the map, summarization and other aggregation tools, heat maps, kernel density are useful for the administrations, although experts might see them as simple, subjective and perceptive models. This could be the case of simple heat maps, which are merely simple spatial distribution maps, which nevertheless help non-experts to easily spot critical areas. Simple spatial distribution tools are an elementary but powerful tool 
for any party involved in the planning process. Considering the size Petru Daniel Măran of the region's area, it was observed that kernel analysis using a search radius of $6000 \mathrm{~m}$, six times the value of the observed mean distance, resulted in an outcome which was more relevant for highlighting clustering trends. For further kernel density analyses, an even greater value of the cell size should be used, a more representative value of the observed mean distance multiplier in relationship with the length of the network and size of the area under study.

As a result, black corridors and vulnerable municipalities were identified.

The results of the Global Moran analysis indicated a strong spatial autocorrelation of the accidents and fatalities. This allowed conducting a more complex pattern analysis within the hotspot analysis. Hotspots were identified for both accidents and fatalities. They provide a statistically relevant result concerning the critical areas in the region where accident clusters and fatality clusters occur. The regional urban centre of Cluj-Napoca is the most vulnerable city, according to the results of the accidents hotspot analysis. The accidents hotspots are clustered around the city, including the municipalities in the metropolitan area of Cluj-Napoca. These critical areas with many accidents involving HGV, LGV and PT vehicles need reconfiguration of the road network. Local, regional and national administrations should focus on these areas. The shortcomings of the road network include low density, lack of motorways, express roads and bypasses that ultimately result in accidents with enormous social and material costs. A clear example in this respect is the number of victims involved in road accidents, and especially the number of fatalities. More critical areas are identified based on the results of the fatalities hotspot analysis. The fatalities hotspots are more numerous compared to the accidents hot spots, the results of their analysis open two different perspectives. On the one hand, the level vulnerability appears to be more gradual among municipalities, as different levels of confidence hotspots are revealed by the analysis. Fatalities hotspots show that critical areas are found in important urban municipalities and wider areas clustered around them. It is the case of the metropolitan area of Oradea located near the border, the regional pole of Cluj-Napoca and some linear municipalities situated on the main road network in BN. On the other hand, some municipalities demonstrate a totally different situation, an opposite trend highlighted by the cold spots, which present a desirable goal - statistically relevant safe areas.

Based on the results of the fatalities hotspot analysis, a municipality could be classified according to the road's potential level of danger considering the reliability level of the pattern. Therefore, 
the most relevant hotspots (99\%) define the most critical areas, named extremely dangerous municipalities. This is the case of the metropolitan area of Oradea and Cluj-Napoca with the municipalities clustered around it (red cells in Figure 6e). Relevant hotspots (95\%) define very critical areas, named very dangerous municipalities. This is the case of municipalities located in the proximity of the metropolitan area of Oradea and of Cluj-Napoca and some of them are linear municipalities, especially in $\mathrm{BH}, \mathrm{CJ}$ and BN county, located on the main road network (orange cells in Figure 6e). Critical areas are defined by hotspots $(90 \%)$ and named dangerous municipalities. These are some linear municipalities located on the main road network (yellow cells in Figure 6e). Therefore, the urgency for intervention has been highlighted along setting priorities for improvements of the road transport network to reduce the number of lives lost every year. These envision construction of new motorways, expressways, ring roads, bypasses, and collector streets in the municipalities, especially cities and linear municipalities.

Furthermore, the results of this research may enable the planners and administrations to act strategically for improving road safety in the critical areas, to prioritize the actions for road network development and to formulate better strategies in road safety.

Based on the results of the research, the future version of The National Strategy for Road Safety should include a specific objective in order to state the need for an improved road network. In this respect, improving the transportation system in the region should be carried out through the development of a reliable road network, which implies higher road density and dedicated infrastructure for high-speed and goods vehicles. In addition to road network improvements, the document should also consider the need for appropriate facilities for goods and passenger road transport, which are also very important factors for the drivers and could help increase the safety of goods and passenger transport.

According to the findings presented in the paper, another specific objective in the strategic plan should also refer to reviewing the planning and urban development norms, as well as including details referring to urbanization along the main transit roads - European, national, county - to limit the linear development of the existing municipalities along these. In this respect, it is necessary to restrict construction in the areas adjacent to the transit and bypass arteries. Care should be taken to avoid situations where bypasses and ring roads become local and access roads through the development of adjacent urban areas. Therefore, improving the road network by building appropriate infrastructure for high-speed and goods transport should 
improve road safety and result in the reduction of both social and Mara Dumitrescu, Petru Daniel Măran material costs in a holistic way, in an integrated planning process.

The paper has presented the first attempt to develop a methodology to study road safety at the regional level in Romania. It presented the statistical analyses and GIS analyses conducted within the case study. The complex accidents database, which provided the basis for this research, could be improved to include such variable as vehicle category according to the Romanian traffic norms in the characteristics recorded in the data collection process conducted at accident sites.

As a further step of this research, it is important to establish a specific correlation between traffic volume and accidents or fatalities. A different administrative level should also be considered in the future analysis with the focus on municipalities in order to establish the relationship between such variables as road network density, accident rate, fatality rate, traffic volumes, etc.

\section{Acknowledgements}

This paper is supported by the Programme ExNanoMat-21PFE (Sustinerea excelentei in cercetarea din domeniul nanotehnologiilor si materialelor avansate).

The Traffic Department of the General Inspectorate of Romanian Police (TDGIRP) supported the research providing access to the database regarding road accidents in the North-West Region of Romania for the period between 2015 and 2018.

Transport Systems Research Group - Technical University of ClujNapoca supported the research with Excel and ArcGIS platforms for the analyses.

\section{REFERENCES}

Benedek, J., \& Kurkó, I. (2012). Convergence or Divergence? The Position of Romania in the Spatial Structure of the European Union. Transylvanian Review, 21(2), 116-125.

Benedek, J., Ciobanu, S. M., \& Man, T. C. (2016). Hotspots and Social Background of Urban Traffic Crashes: A Case Study in Cluj-Napoca (Romania). Accident Analysis \& Prevention, 87, 117-126. https://doi.org/10.1016/j.aap.2015.11.026

Björnstig, U., Björnstig, J., \& Eriksson, A. (2008). Passenger Car Collision Fatalities - With Special Emphasis on Collisions With Heavy Vehicles. Accident Analysis \& Prevention, 40(1), 158-166.

https://doi.org/10.1016/j.aap.2007.05.003 
Cadar, R. D., Boitor, R. M., \& Dumitrescu, M. (2017). Effects of Traffic Volumes on Accidents: The Case of Romania's National Roads. Geographia Technica, 12(2), 20-29. https://doi.org/10.21163/gt_2017.122.03

Ciobanu, S. M., \& Benedek, J. (2015). Spatial Characteristics and Public Health Consequences of Road Traffic Injuries in Romania. Environmental Engineering and Management Journal, 14(11), 2689-2702. https://doi.org/10.30638/eemj.2015.286

Coșciug, A., Ciobanu, S., \& Benedek, J. (2017). The Safety of Transnational Imported Second-Hand Cars: A Case Study on Vehicle-to-Vehicle Crashes in Romania. Sustainability, 9(12), 2380. https://doi.org/10.3390/su9122380

European Commission. (2018a). Annual Accident Report. European Commission, Directorate General for Transport.

European Commission. (2018b). Traffic Safety Basic Facts on Heavy Goods Vehicles and Buses. European Commission, Directorate General for Transport.

European Commission. (2019). Fact Sheet. 2018 Road Safety Statistics: What Is Behind the Figures? Retrieved from https://europa.eu/rapid/press-release_ MEMO-19-1990_en.htm

Eurostat. (2017). Statistics Explained. Passenger Cars in the EU. Retrieved from https://ec.europa.eu/eurostat/statistics-explained/index.php/Passenger_ cars_in_the_EU

Eurostat. (2019). Road, Rail and Navigable Inland Waterways Networks by NUTS 2 Regions. Retrieved from https://appsso.eurostat.ec.europa.eu/nui/show. do?dataset=tran_r_net\&lang $=$ en

Ivan, K., Haidu, I., Benedek, J., \& Ciobanu, S. M. (2015). Identification of Traffic Accident Risk-Prone Areas Under Low-Light Conditions. Natural Hazards and Earth System Sciences, 15(9), 2059-2068. https://doi.org/10.5194/nhess-15-2059-2015

Knoema. (n. d.). Road Density. Retrieved from https://knoema.com/atlas/topics/ Transportation/Road-transport/Road-density

Kofalvi, G., \& Vincze-Pap, S. (2001). Traffic Safety of Heavy Vehicles (Accident Analysis, Accident Reconstruction). In Proceedings of the International Technical Conference on the Enhanced Safety of Vehicles (p. 244).

Lindberg, G. (2006). External Accident Cost of Heavy Goods Vehicles. Retrieved from Digitala Vetenskapliga Arkivet: http://urn.kb.se/resolve?urn=urn:nbn: se:oru:diva-3185

OpenStreetMap. (n. d.). Retrieved from opendatacommons.org

Pirotti, F., Guarnieri, A., \& Vettori, A. (2011). Collaborative Web-GIS Design: A Case Study for Road Risk Analysis and Monitoring. Transactions in GIS, 15(2), 213-226. https://doi.org/10.1111/j.1467-9671.2011.01248.x

Romania National Institute for Statistics. (2018). Transport Equipment, Vehicles Registered and Road Traffic Accidents. Retrieved from http://www.insse.ro/ $\mathrm{cms} / \mathrm{ro} / \mathrm{content} / \mathrm{mijloace}$-de-transport-vehicule-înmatriculate-și-accidentede-circulație-rutieră

Romania National Institute for Statistics. (2019). TEMPO-Online Statistical Databases. Retrieved from http://statistici.insse.ro:8077/tempo-online/\#/ pages/tables/insse-table 
Romanian INSPIRE Geoportal. (n. d.). INIS Geoportal. Retrieved from Administrative limits: http://geoportal.gov.ro/Geoportal_INIS/

Thakali, L., Kwon, T. J., \& Fu, L. (2015). Identification of Crash Hotspots Using Kernel Density Estimation and Kriging Methods: A Comparison. Journal of Modern Transportation, 23(2), 93-106. https://doi.org/10.1007/s40534-015-0068-0

Mara Dumitrescu, Petru Daniel Măran

Investigating Accidents on the Main Road Network

The Government of Romania. (2014). Government Decision no. 782 for Amending the Annexes to Government Decision no. 540/2000 Regarding the Approval of the Classification Into Functional Categories of Public Roads and Private Utility Roads Open to Public Circulation. Retrieved from http://sitevechi. cnadnr.ro/HG\%20782-2014\%20INCADRAREA\%20DRUMURILOR\%20IN\%20 CATEGORII\%20FUNCTIONALE.pdf

The National Strategy for Road Safety for the Period 2015-2020. (n. d.). Retrieved from http://www.mmediu.ro/app/webroot/uploads/files/2015-07-28_ Strategie_Siguranta_Rutiera_2015.pdf

Wachnicka, J., Kustra, W., Jamoroz, K., \& Budzynski, M. (2016). Development of Tools for Road Infrastructure Safety Management for the Provinces (Voivodeships) in Poland. Risk, Reliability and Safety: Innovating Theory and Practice, 433-440. https://doi.org/10.1201/9781315374987-67

\section{NOTATIONS}

\section{Abbreviations}

EU - the European Union;

N-W Region - North-West Region of Romania;

BH - Bihor County;

BN - Bistrița-Năsăud County;

CJ - Cluj Cunty;

MM - Maramureș County;

SM - Satu Mare County;

SJ - Sălaj County;

OSM - OpenStreetMap;

NIS - the National Institute for Statistics - ROMANIA;

TDGIR - Traffic Department of the General Inspectorate of Romanian Police;

HGV - Heavy Goods Vehicles, Heavy Gross Vehicles;

LGV - Light Goods Vehicles;

PT - Public Transport vehicles or passenger vehicles transporting a larger number of people;

AR - Accident Rate;

FR - Fatality Rate;

GIS - Geographic Information System. 